\title{
The effect of eating fortified breakfast cereal on the micronutrient intake of adults between the ages of 19 and 64 years
}

\author{
G. L. Warburton and C. Hunt \\ School of Applied Sciences, University of Huddersfield, HDI 3DH, UK
}

Breakfast is often regarded as the most important meal of the day ${ }^{(1)}$ and findings have shown breakfast eaters to be slimmer ${ }^{(2)}$, have $\mathrm{BMI}^{(2)}$, have a lower percentage intake of fat in the diet and higher percentage intakes of carbohydrates, dietary fibre and certain micronutrients ${ }^{(3)}$. Additionally, for those people who skip breakfast, any deficit in micronutrient intake appears to not be compensated for at other mealtimes ${ }^{(1)}$.

A convenience sample of 24 adults was recruited and classified into two groups - those who regularly consumed ready to eat breakfast cereal ( $n 16$ 'RTEC eaters') and those that either did not consume breakfast at all or chose to eat foods other than RTEC ( $n 8$ 'non-RTEC eaters'). In study week 1, the participants were asked to complete a 3-d weighed food diary, to act as a control, and a questionnaire to determine their current breakfast habits. In study week 2, the intervention week, the participants were provided with a $30 \mathrm{~g}$ portion of corn flakes to eat each day as 'breakfast' and asked to complete another $3 \mathrm{~d}$ weighed food diary. The food diaries were analysed using Microdiet, paired $t$-tests and one sample $t$-tests.

Overall, the results were inconclusive as to whether fortified RTEC had a direct effect on the micronutrient intakes of the adults. In a comparison of the groups between study week 1 to study week 2, the RTEC eaters displayed a significant decrease in calcium and decreases in almost all of the other micronutrients except for folate. The non-RTEC eaters displayed a significant increase in folate intakes and increases in almost all of the other micronutrients, but for both groups it was impossible to say conclusively whether this was due to the inclusion of RTEC in their diets or the type of RTEC used in study week 2 or to variation in their dietary habits between the study weeks.

\begin{tabular}{|c|c|c|c|c|c|c|}
\hline \multirow[b]{3}{*}{ Nutrient } & \multicolumn{6}{|c|}{ Mean nutrient intakes } \\
\hline & \multicolumn{3}{|c|}{ RTEC eaters $(n$ 16) } & \multicolumn{3}{|c|}{ Non-RTEC eaters $(n 8)$} \\
\hline & Wk 1 & Wk 2 & Sig. & Wk 1 & Wk 2 & Sig. \\
\hline Thiamin (mg) & 2.0 & 1.7 & 0.14 & 1.3 & 1.5 & 0.37 \\
\hline Riboflavin (mg) & 2.3 & 2.1 & 0.51 & 1.5 & 1.9 & 0.07 \\
\hline Niacin (mg) & 30.0 & 24.8 & 0.09 & 23.9 & 19.2 & 0.12 \\
\hline Vitamin $B_{6}(\mathrm{mg})$ & 2.8 & 2.5 & 0.14 & 2.1 & 2.1 & 0.91 \\
\hline Vitamin $B_{12}(\mu \mathrm{g})$ & 7.4 & 7.3 & 0.91 & 5.6 & 5.8 & 0.87 \\
\hline Folate $(\mu \mathrm{g})$ & 323.0 & 326.8 & 0.87 & 226.6 & 305.7 & 0.01 \\
\hline Vitamin $\mathrm{D}(\mu \mathrm{g})$ & 3.2 & 2.8 & 0.67 & 2.1 & 1.7 & 0.34 \\
\hline $\mathrm{Na}(\mathrm{mg})$ & 3092.7 & 2885.7 & 0.57 & 2131.2 & 2341.3 & 0.65 \\
\hline $\mathrm{Ca}(\mathrm{mg})$ & 1019.1 & 836.6 & 0.05 & 678.4 & 802.9 & 0.30 \\
\hline $\mathrm{Fe}(\mathrm{mg})$ & 13.8 & 12.1 & 0.22 & 8.1 & 9.3 & 0.08 \\
\hline
\end{tabular}

In conclusion, beginning to eat RTEC was associated with a minor increase in micronutrient intake. Changing the cereal eaten was associated with a minor deficit in micronutrient intake. This suggests that the consumption of RTEC is associated with micronutrient intake.

1. Affenito SG (2007) Breakfast: a missed opportunity. J Am Diet Assoc 107, 565-569.

2. De la Hunty A \& Ashwell M (2007) Are people who regularly eat breakfast cereals slimmer than those who don't? A systematic review of the evidence. Nutr Bull 32, 118-128.

3. Rogers P (1997) How important is breakfast? Br J Nutr 78, 197-198. 